\title{
The (Eternal) Debate on Microwave Ablation Versus Radiofrequency Ablation in BCLC-A Hepatocellular Carcinoma
}

\author{
ANGELA DALIA RICCI ${ }^{*}$, ALESSANDRO RIZZO $^{1 *}$, CHIARA BONUCCI $^{1}$, SIMONA TAVOLARI $^{2}$, \\ ANDREA PALLONI ${ }^{1}$, GIORGIO FREGA ${ }^{1}$, VERONICA MOLLICA ${ }^{1}$, NASTASSJA TOBER ${ }^{1}$, \\ ELENA MAZZOTTA ${ }^{3}$, CRISTINA FELICANI $^{3}$, CARLA SERRA $^{3}$ and GIOVANNI BRANDI ${ }^{1}$ \\ ${ }^{1}$ Department of Experimental, Diagnostic and Specialty Medicine, \\ S. Orsola-Malpighi University Hospital, Bologna, Italy; \\ ${ }^{2}$ Center of Applied Biomedical Research, S. Orsola-Malpighi University Hospital, Bologna, Italy; \\ ${ }^{3}$ Department of Organ Insufficiency and Transplantation, S. Orsola-Malpighi Hospital, Bologna, Italy
}

\begin{abstract}
Background/Aim: While percutaneous radiofrequency ablation (RFA) is considered the standard ablative modality for the treatment of early-stage hepatocellular carcinoma (HCC), percutaneous microwave ablation (MWA) is being increasingly used in recent years. We performed a systematic review and meta-analysis to compare percutaneous $M W A$ versus percutaneous RFA in BCLC-A HCC across randomized controlled trials (RCTs). Patients and Methods: Eligible studies included RCTs assessing MWA versus RFA in $B C L C-A$ HCC. Outcomes of interest included: complete ablation (CA) rate, local recurrence $(L R)$ rate, 1-year overall survival $(O S)$ rate, 3-year OS rate and major complications rate. Results: We retrieved all the relevant RCTs through PubMed/Medline, Cochrane library and EMBASE; five eligible studies involving a total of 794 patients (MWA: 409; RFA: 385) and 1008 nodules of HCC (MWA: 519; RFA: 489) were included in our analysis. No significant differences were found between MWA and RFA regarding CA, LR, 3-year OS and major complications rate. Regarding 1-year OS, a higher rate was observed in the MWA group. Conclusion: MWA and RFA are effective and safe techniques in early stage, BCLC-A, HCCMWA resulted in better 1-year OS, although this benefit was not confirmed in the 3-year analysis.
\end{abstract}

This article is freely accessible online.

*These Authors contributed equally to this study.

Correspondence to: Alessandro Rizzo, Department of Experimental, Diagnostic and Specialty Medicine, S. Orsola-Malpighi University Hospital, Bologna, Italy. Tel: +39 0512144078, Fax: +39 0516364037,e-mail: rizzo.alessandro179@gmail.com

Key Words: Hepatocellular carcinoma, liver cancer, radiofrequency ablation, microwave ablation.
Hepatocellular carcinoma (HCC) is one of the leading causes of cancer-related deaths worldwide (1). It currently represents the fifth most common malignancy among men and the seventh in women, with an increasing incidence due to which HCC is supposed to become the third leading cause of cancer-related deaths in western countries by $2035(2,3)$. Radical removal of the tumor is the only potentially curative treatment for HCC (4); however, more than half of HCC cases are detected when advanced (locally advanced/ unresectable or metastatic) and the majority of patients can receive only palliative treatments, with poor prognosis and short life expectancy (5-7).

Several staging and classification systems have been used and proposed for HCC, in order to define the "double-headed" nature of the disease, with prognosis and treatment depending on tumor burden, hepatic functional reserve and patient's underlying liver disease (8). Among them, the Barcelona Clinic Liver Cancer Classification (BCLC) is probably the most widely used worldwide (9); according to this system, very early (BCLC-0) and early-stage (BCLC-A) HCC are amenable to curative treatments, including radical surgical resection, liver transplantation and tumor ablation $(10,11)$. The possibility to obtain complete removal of the tumor at this stage has led to the development of several minimally invasive treatment options including radiofrequency ablation (RFA), microwave ablation (MWA), cryoablation and percutaneous ethanol injection (PEI) (12-14). Moreover, the combination of systemic treatments with locoregional techniques has been also investigated and there are currently ongoing trials aimed to evaluate efficacy and safety of multimodal treatments (15, 16). Local ablative strategies such as percutaneous RFA and percutaneous MWA have shown to be safe and feasible in HCC, where RFA represents the most frequently used ablative modality in unresectable BCLC-A HCC, reaching outcomes comparable to those of surgical resection in case of single nodules less than $2 \mathrm{~cm}$ in size (17). 


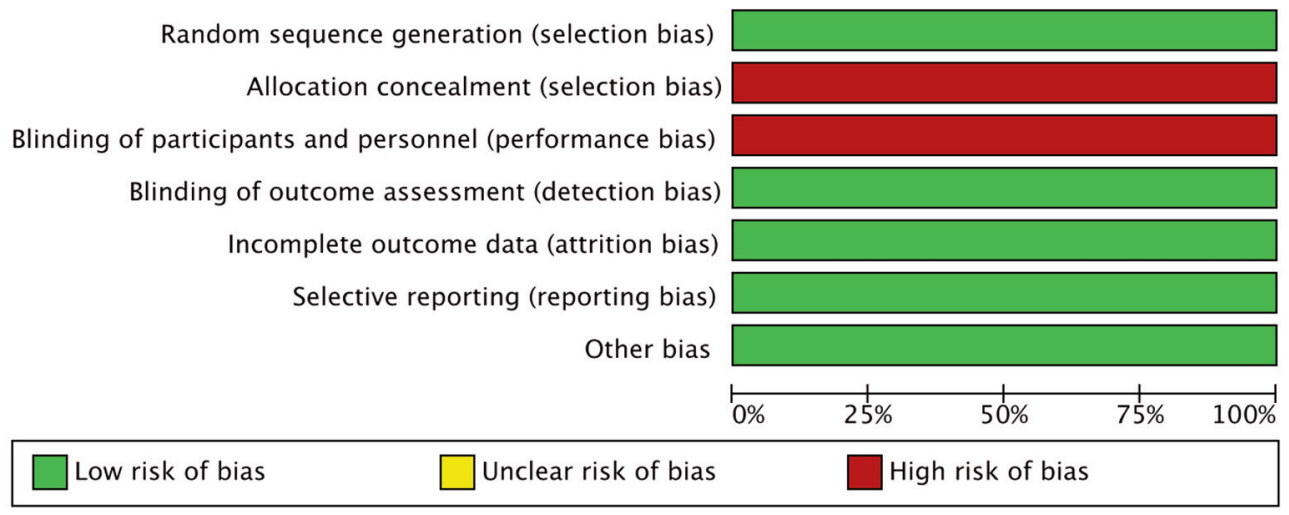

Figure 1. Risk of bias graph: Authors' judgements on each risk of bias item presented as percentages across all included studies.

The comparison between MWA and RFA is currently under debate, and several meta-analyses have found that the two modalities have similar efficacy and safety $(18,19)$. However, previous studies presented several limitations, given the inclusion of primary and secondary liver malignancies and HCCs at different stages. Finally, the two modalities have been mostly compared through retrospective analysis of single center cohorts, with no level 1 data supporting the superiority of RFA or MWA.

In the current study, we performed a systematic review and meta-analysis to examine complete ablation (CA) rate, local recurrence (LR) rate, 1-year overall survival (OS) rate, 3 -year OS rate at and major complications rate in patients receiving percutaneous MWA or percutaneous RFA for BCLC-A HCC, across 5 RCTs (20-24).

\section{Patients and Methods}

Search strategies. All phase II and phase III clinical trials published from June 15, 2000 to March 26, 2020 regarding the clinical role of MWA and RFA in BCLC-A HCC were retrieved by 2 different authors (AR and ADR). Keywords used for searching on PubMed/Medline, Cochrane Library and EMBASE were: "Radiofrequency Ablation" OR "Microwave Ablation" OR "Locoregional Therapies" OR "Ablative Treatments" AND "HCC" OR "hepatocellular carcinoma" OR "liver cancer"; only articles published in peer-reviewed journals and written in English language were considered. Furthermore, proceedings of the main international oncological meetings (American Society of Clinical Oncology, European Society of Medical Oncology, European Council of Clinical Oncology, American Association for Cancer Research), were also searched from 2000 onward for relevant abstracts.

Selection criteria. Studies selected from first analysis were then restricted to: 1) prospective phase II or III randomized controlled trials (RCT) in early stage, BCLC-A, HCC; 2) participants enrolled in percutaneous MWA arm or percutaneous RFA arm; 3) studies with available data about clinical outcomes. All patients had the sequent tumor burden: A) three or less HCC lesions with no lesion more than $5 \mathrm{~cm}, \mathrm{~B}$ ) no evidence of extrahepatic metastasis and/or vascular invasion.

Data extraction and quality assessment. The following data were extracted for each publication: 1) study general information (author, year, carry out country, inclusion criteria); 2) interventions; 3) number of patients; 4) number of nodules; 5) available outcomes in terms of CA rate, LR rate, 1-year OS rate, 3-year OS rate and major complications rate. Two separate authors (AR and ADR) conducted the search and identification independently.

We assessed the methodological quality of the included trials using the Cochrane Collaboration tool. Studies examined were graded as having a "low risk", "high risk", or "unclear risk" of bias across the 7 specified domains. This meta-analysis was conducted according to Preferred Reporting Items for Systematic Review and Meta-Analyses (PRISMA) guidelines (25).

Assessment of risk of bias in included studies. Risk of bias in the five selected studies (20-24) was assessed independently by two authors (AR and ADR) using the tool of The Cochrane Collaboration for assessing risk of bias and therefore including selection, performance, detection, attrition and reporting bias (26). The lists of outcomes reported in the published paper were compared to those from study protocols or trials registries. The results are summarized in a risk of bias graph (Figure 1).

Types of outcome measures

We examined five outcomes:

- CA rate, defined as complete ablation of the tumor shown on imaging follow-up 1 month after percutaneous MWA or percutaneous RFA.

- LR rate, defined as any new lesion developing inside or adjacent to the ablated zone.

- 1-year OS rate and 3-year OS rate. The 1-year OS rate and the 3-year OS were defined as the number of patients alive after 12 and 36 months, respectively.

- Major complications rate. According to the Clavien-Dindo Staging (27), grade 3 or higher complications were defined as major complications.

All data were obtained from full text or supplementary material of each study. 


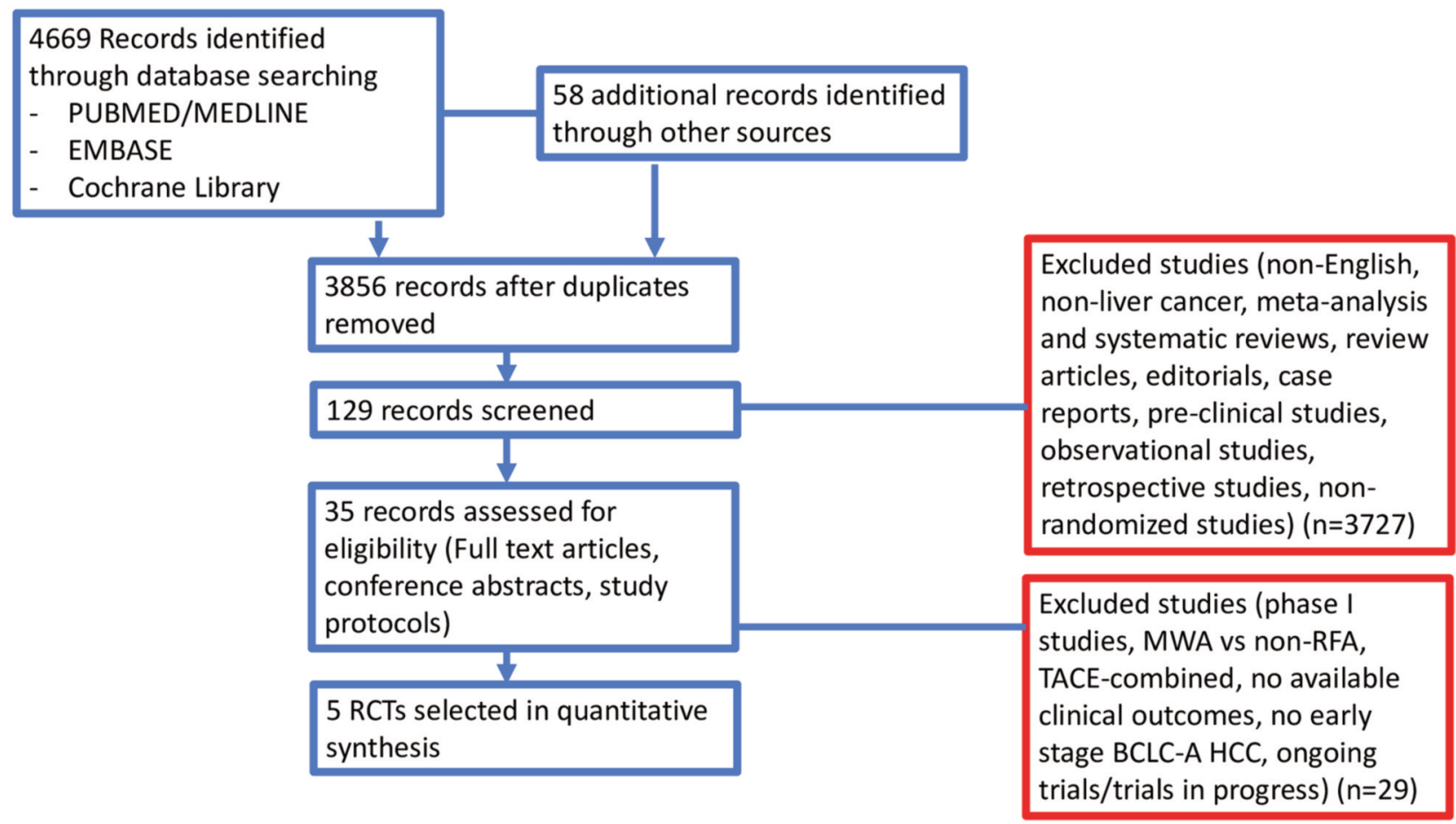

Figure 2. Study flow diagram.

Statistical analysis. All statistical analyses were performed using $\mathrm{R}$ studio. Results about CA, LR, OS and major complications rate were compared by calculating Odds Ratio (OR) with $95 \%$ confidence intervals (CIs); ORs were combined with the Mantel-Haenszel method. Statistical heterogeneity between studies was examined using the Chi-square test and the $\mathrm{I}^{2}$ statistic; substantial heterogeneity was considered to exist when the $\mathrm{I}^{2}$ value was greater than $50 \%$ or there was a low $p$-value $(<0.10)$ in the Chi-square test.

\section{Results}

Studies selected. In our search, we identified 637 potentially relevant reports, which were subsequently restricted to eight after an independent evaluation by 2 authors (AR and ADR). We excluded 629 records as non-pertinent reports (metaanalysis and systematic reviews, review articles, editorials, case reports, retrospective studies, non-randomized studies, ongoing trials/trials in progress). Moreover, we excluded two trials comparing MWA and RFA in primary and secondary liver malignancies $(28,29)$ and another trial assessing the comparison between transarterial chemoembolization combined with MWA or RFA in HCC (30).

All studies included in our analysis (20-24) were published as full manuscripts and were judged as studies with a low risk of bias in separate reviews by 2 authors (AR and ADR). Figure 2 shows the search process.

The five studies (20-24) were all randomized trials including patients affected by early stage, BCLC-A HCC who were deemed suitable for locoregional therapies. A total of 794 patients (MWA: 409; RFA: 385) and 1008 nodules of HCC (MWA: 519; RFA: 489) were available for the metaanalysis. A summary of the included RCTs is presented in Table I. All five RCTs (20-24) had reported data on LR rate and major complications rate. Four trials had reported data on CA rate while three studies had reported data on 1-year and 3-year OS rates.

Complete ablation rate. In order to evaluate $\mathrm{CA}$ rate, data were extracted from 4 RCTs (21-24) comprising 806 nodules. No differences in CA rate between percutaneous MWA and percutaneous RFA were detected in the analysis $(\mathrm{OR}=1.21$; 95\% CI=0.52-2.80) (Figure 3$)$; results were associated with low heterogeneity $\left(\mathrm{I}^{2}=5 \%\right)$, therefore a fixed effects model was used.

Local recurrence rate. Five RCTs (20-24) provided data on LR rate in 1008 nodules. The analysis was associated with significant heterogeneity between trials $\left(\mathrm{I}^{2}=60 \%\right)$, and the random-effects model yielded an OR of 0.78 (95\%CI=0.361.69) (Figure 4), showing no significant differences between the two ablative modalities.

1-year overall survival rate. Data were available in 3 RCTs (20-24) comprising 570 patients. Results were associated with low heterogeneity $\left(\mathrm{I}^{2}=32 \%\right)$ and a fixed effects model 
Table I. Summary of the included studies.

\begin{tabular}{|c|c|c|c|c|c|c|c|c|}
\hline $\begin{array}{l}\text { Author/year } \\
\text { (ref.) }\end{array}$ & Country & $\begin{array}{l}\text { Study } \\
\text { design }\end{array}$ & $\begin{array}{l}\text { Inclusion } \\
\text { criteria }\end{array}$ & $\begin{array}{l}\text { Type of } \\
\text { treatment }\end{array}$ & $\begin{array}{l}\text { Sample } \\
\text { size }\end{array}$ & $\begin{array}{l}\text { Median age, } \\
\text { years (range) }\end{array}$ & $\begin{array}{l}\text { Number } \\
\text { of nodules }\end{array}$ & $\begin{array}{l}\text { Size, mean } \\
(\mathrm{SD}, \mathrm{mm})\end{array}$ \\
\hline \multirow[t]{2}{*}{$\begin{array}{l}\text { Kamal/ } \\
2019(23)\end{array}$} & \multirow[t]{2}{*}{ Egypt } & $\begin{array}{l}\text { Monocentric } \\
\text { randomized }\end{array}$ & $\begin{array}{l}\mathrm{HCC} \text { lesions } \leq 3 \\
\text { measuring } \leq 50 \mathrm{~mm}\end{array}$ & RFA & 28 & NR & 34 & $3.28(0.91)$ \\
\hline & & $\begin{array}{l}\text { controlled } \\
\text { trial }\end{array}$ & $\begin{array}{l}\text { and with no vascular } \\
\text { invasion or } \\
\text { extrahepatic spread. }\end{array}$ & MWA & 28 & & 28 & $3.25(0.92)$ \\
\hline \multirow[t]{2}{*}{$\begin{array}{l}\text { Vietti Violi/ } \\
2018 \text { (20) }\end{array}$} & \multirow{2}{*}{$\begin{array}{c}\text { Switzer- } \\
\text { Land, } \\
\text { France }\end{array}$} & \multirow{2}{*}{$\begin{array}{l}\text { Multicentre } \\
\text { randomized } \\
\text { controlled } \\
\text { trial }\end{array}$} & $\begin{array}{c}\text { HCC lesions } \leq 3 \\
\text { measuring } \leq 40 \mathrm{~mm},\end{array}$ & MWA & 71 & $68(60-72)$ & 98 & $18(6.5)$ \\
\hline & & & $\begin{array}{l}\text { related to chronic liver } \\
\text { disease (hepatitis) or } \\
\text { cirrhosis with Child-Pugh } \\
\text { score A or B and adequate } \\
\text { pre-ablation imaging } \\
\text { done within } 4 \text { weeks before } \\
\text { starting the intervention. }\end{array}$ & RFA & 73 & 65 (59-73) & 104 & $18(7.1)$ \\
\hline \multirow[t]{2}{*}{$\begin{array}{l}\mathrm{Yu} / \\
2017(22)\end{array}$} & \multirow[t]{2}{*}{ China } & \multirow{2}{*}{$\begin{array}{l}\text { Monocentric } \\
\text { randomized } \\
\text { controlled } \\
\text { trial }\end{array}$} & $\begin{array}{c}\mathrm{HCC} \text { lesions } \leq 3 \\
\text { measuring } \leq 50 \mathrm{~mm}\end{array}$ & MWA & 203 & NR & 265 & $2.7(1.0)$ \\
\hline & & & $\begin{array}{l}\text { and with no vascular } \\
\text { invasion or extrahepatic } \\
\text { spread, Child-Pugh class A } \\
\text { or B, lesions visible on } \\
\text { ultrasound with an acceptable } \\
\text { puncture path, ECOG 0-1, } \\
\text { and no other anticancer } \\
\text { treatment previously. }\end{array}$ & RFA & 200 & & 251 & $2.6(1.0)$ \\
\hline \multirow[t]{2}{*}{$\begin{array}{l}\text { Abdelaziz/ } \\
2014(24)\end{array}$} & \multirow[t]{2}{*}{ Egypt } & \multirow{2}{*}{$\begin{array}{l}\text { Monocentric } \\
\text { randomized } \\
\text { controlled } \\
\text { trial }\end{array}$} & $\begin{array}{l}\text { HCC early stage with } \\
\text { lesions } \leq 3 \text {, measuring }\end{array}$ & RFA & 45 & $56.8(\mathrm{NR})$ & 52 & $2.95(1.03)$ \\
\hline & & & $\begin{array}{c}\leq 50 \mathrm{~mm} \text {, PS } 0 \text { and proper } \\
\text { coagulation profile. Patients } \\
\text { eligible for resection } \\
\text { or liver transplantation } \\
\text { but not feasible were also } \\
\text { included. }\end{array}$ & MWA & 66 & $53.6(\mathrm{NR})$ & 76 & $2.9(0.97)$ \\
\hline \multirow[t]{2}{*}{$\begin{array}{l}\text { Shibata/ } \\
2002(21)\end{array}$} & \multirow[t]{2}{*}{ Japan } & $\begin{array}{l}\text { Monocentric } \\
\text { randomized }\end{array}$ & $\begin{array}{l}\text { HCC single lesion } \\
\text { measuring }<40 \mathrm{~mm}\end{array}$ & RFA & 36 & $63.6(44-83)$ & 48 & $2.3(1.0-3.7)$ \\
\hline & & $\begin{array}{l}\text { controlled } \\
\text { trial }\end{array}$ & $\begin{array}{c}\text { or lesions } \leq 3 \\
\text { measuring } \leq 30 \mathrm{~mm} .\end{array}$ & MWA & 36 & $62.5(52-74)$ & 46 & $2.2(0.9-3.4)$ \\
\hline
\end{tabular}

SD: Standard deviation; HCC: hepatocarcinoma; ECOG: Eastern Cooperative Oncology Group; PS: performance Status; RFA: radiofrequency ablation; MWA: microwave ablation; NR: not reported.

was used; overall OR was in favour of percutaneous MWA $(\mathrm{OR}=1.9 ; 95 \% \mathrm{CI}=1.03-3.51)$ (Figure 5).

3-year overall survival rate. The 3-year OS rate was reported by 3 RCTs (22-24) with 666 patients. No heterogeneity was found for these studies $\left(\mathrm{I}^{2}=0 \%\right)$; hence, the fixed-effects model was used (Figure 6). No significant difference in the 3 -year $\mathrm{OS}$ rate was detected $(\mathrm{OR}=1.17$; $95 \% \mathrm{CI}=0.81-1.70$ ).

Major complications rate. All the RCTs (20-24) reported data about major complications occurring within 1 month after the ablative technique. No significant differences were found $(\mathrm{OR}=1.11 ; 95 \% \mathrm{CI}=0.55-2.23)$ (Figure 7); results were associated with low heterogeneity $\left(\mathrm{I}^{2}=32 \%\right)$, therefore a fixed effects model was used.

\section{Discussion}

Due to the development of interventional radiology, locoregional therapies have become an important alternative treatment in early-stage HCC over the last 30 years (31). Among them, RFA and MWA are commonly used ablation techniques which cause coagulative tumor necrosis by directly delivering heat into nodules $(32,33)$. Although the two modalities share some characteristics, RFA and MWA 


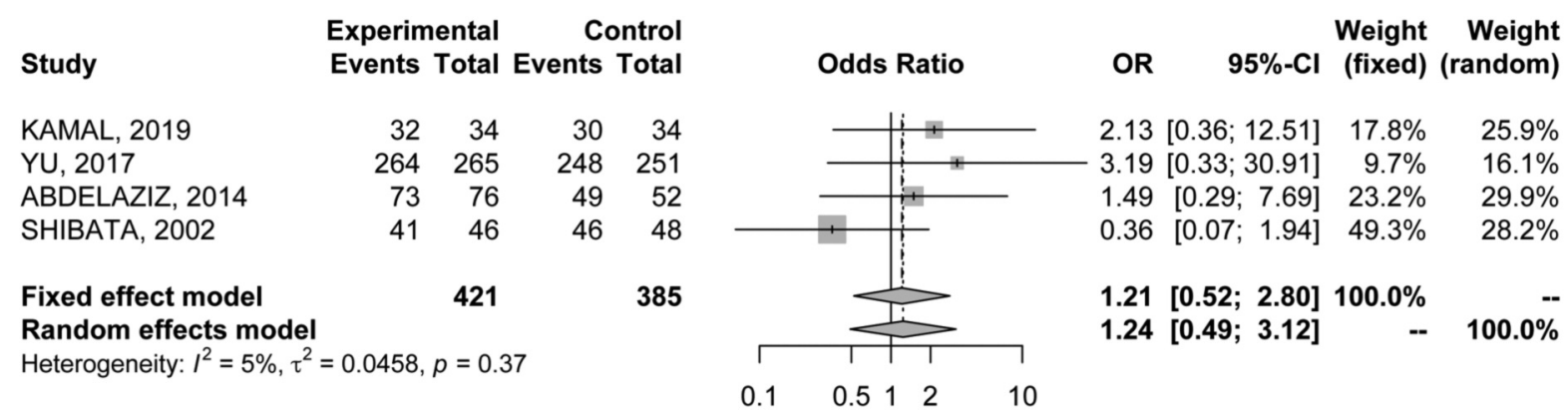

Figure 3. Forest plot of comparison between MWA and RFA; the outcome was Odds Ratio of Complete Ablation (CA) rate. CI: Confidence interval.

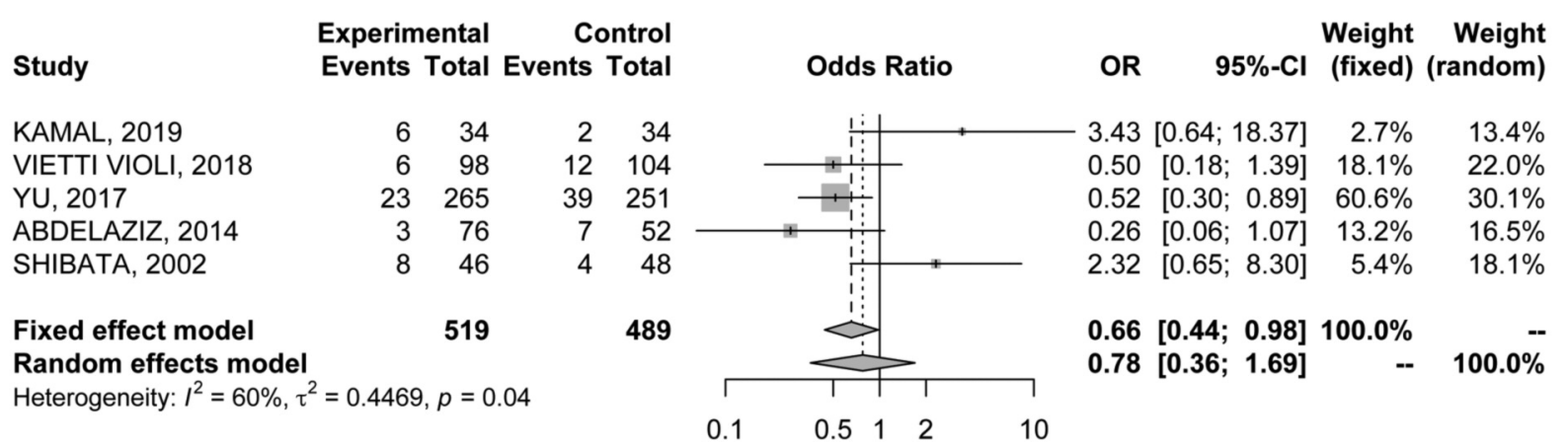

Figure 4. Forest plot of comparison between MWA and RFA; the outcome was Odds Ratio of Local Recurrence (LR) rate. CI: Confidence intervaI.

differ significantly in their mechanism of action: MWA induces tumor necrosis employing electromagnetic waves from electrodes whereas RFA delivers electric current (34). Percutaneous RFA is currently considered an established treatment option in unresectable BCLC-0 and BCLC-A HCCs, as also recommended by the last European Association for the Study of the Liver (EASL) clinical practice guidelines (35). Low major and minor complication rates together with the efficacy and availability of the technique, has led to a wide use of RFA over the last two decades worldwide $(36,37)$. More recently, MWA has been found to be not only an alternative to conventional RFA, but also a potentially superior treatment modality since MWA seems to deliver heat more quickly, requiring less ablation time when compared to percutaneous RFA $(38,39)$. MWA seems also to be less influenced by the heat-sink effect, a thermal effect characterized by heat dispersion due to blood flow in local vessels (40). Moreover, when using RFA, the ablated area is smaller and less predictable because of local tissue charring that acts like an insulator increasing local impedance (41). However, although MWA seems to be superior to RFA, neither prospective nor retrospective trials succeeded in demonstrating any significant difference between the two ablative modalities $(42,43)$.
Thus, the aim of this meta-analysis was to update the already available data with the results of the latest RCTs, providing a clear overview on this specific topic. Five studies (20-24) published between 2002 and 2019 were included in the current meta-analysis for a total of 794 patients and 1008 HCC nodules; the study population was well balanced between RFA and MWA groups in terms of patients and tumors characteristics. No statistically significant difference was detected in terms of CA, LR and major complications rate between the two techniques. Although the outcome was not analyzed in all selected RCTs (20-24), the 1-year OS was significantly improved in the MWA group $(\mathrm{OR}=1.9 ; 95 \% \mathrm{CI}=1.03-3.51)$, but the results were not confirmed at the 3 years analysis $(\mathrm{OR}=1.17$; $95 \% \mathrm{CI}=0.81-1.70)$. CA was evaluated in 4 (21-24) out of 5 RCTs, excluding the study by Vietti Violi (20) where patients were followed-up after achieving complete ablation of all lesions. Despite no statistically significant difference, the assessment of complete response was not pursued in the same way for all RCTs. Shibata and Yu $(21,22)$ considered the final rate of $\mathrm{CA}$ after a different number of ablation sessions (one or more); while Kamal (23) reported the amount of complete ablations after one and two sessions of treatment (then all HCCs in both groups were completely 


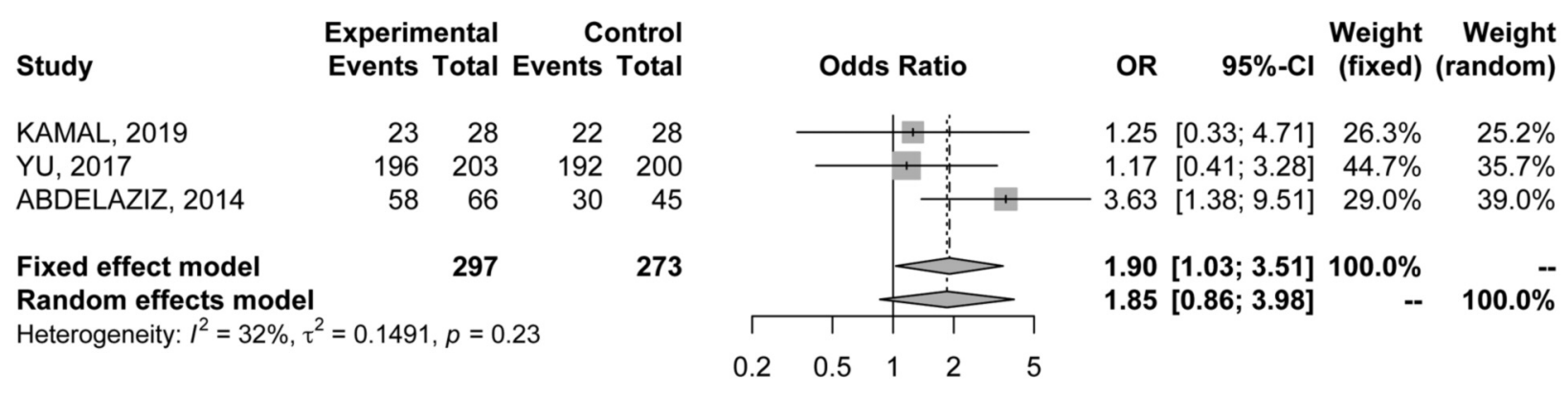

Figure 5. Forest plot of comparison between MWA and RFA; the outcome was Odds Ratio of 1-year Overall Survival (OS) rate. CI: Confidence interval.

\begin{tabular}{|c|c|c|c|c|c|c|c|c|c|}
\hline \multirow{2}{*}{$\begin{array}{l}\text { Study } \\
\text { VIETTI VIOLI, } 2018\end{array}$} & \multicolumn{2}{|c|}{$\begin{array}{l}\text { Experimental } \\
\text { Events Total }\end{array}$} & \multicolumn{2}{|c|}{$\begin{array}{r}\text { Control } \\
\text { ents Total }\end{array}$} & \multirow{2}{*}{ Odds Ratio } & \multirow{2}{*}{$\begin{array}{l}\text { OR } \\
1.00\end{array}$} & \multirow{2}{*}{$\begin{array}{r}95 \%-\mathrm{Cl} \\
{[0.45 ; 2.22]}\end{array}$} & \multicolumn{2}{|c|}{$\begin{array}{r}\text { Weight Weight } \\
\text { (fixed) (random) }\end{array}$} \\
\hline & 61 & 76 & 61 & 76 & & & & $23.4 \%$ & $21.8 \%$ \\
\hline YU, 2017 & 166 & 203 & 163 & 200 & ! & 1.02 & {$[0.62 ; 1.69]$} & $58.2 \%$ & $54.7 \%$ \\
\hline ABDELAZIZ, 2014 & 41 & 66 & 21 & 45 & 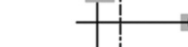 & 1.87 & {$[0.87 ; 4.04]$} & $18.4 \%$ & $23.6 \%$ \\
\hline \multirow{3}{*}{$\begin{array}{l}\text { Fixed effect model } \\
\text { Random effects model } \\
\text { Heterogeneity: } I^{2}=0 \%, \tau^{2}\end{array}$} & & 345 & & 321 & $L_{i}$ & $\begin{array}{l}1.17 \\
1.17\end{array}$ & $\begin{array}{l}{[0.81 ; 1.70]} \\
{[0.81 ; 1.70]}\end{array}$ & $\begin{array}{r}100.0 \% \\
--\end{array}$ & $100.0 \%$ \\
\hline & $=0, p=0$. & & & & & & & & \\
\hline & & & & & 1 & & & & \\
\hline
\end{tabular}

Figure 6. Forest plot of comparison between MWA and RFA; the outcome was Odds Ratio of 3-year Overall Survival (OS). CI: Confidence intervaI.

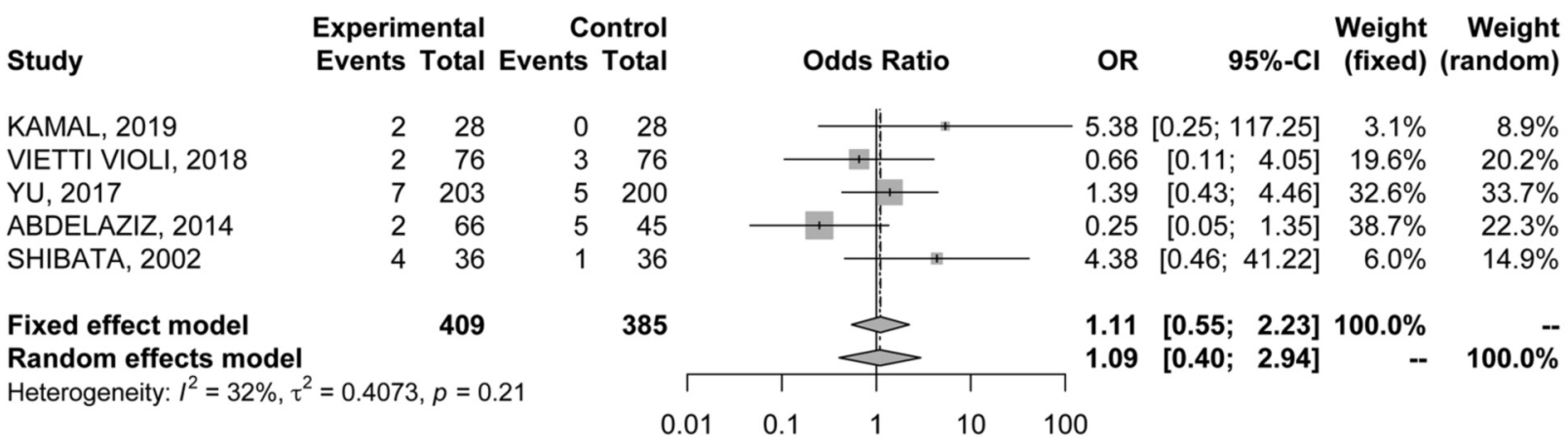

Figure 7. Forest plot of comparison between MWA and RFA; the outcome was Odds Ratio of major complications rate. CI: Confidence intervaI.

ablated) and, in our analysis, we considered CA after one session. Finally, Abdelaziz (24) did not specify whether CA was achieved after one or more ablation sessions. No difference was found in LR rate between the two procedures, with only a slight trend in favor of MWA. This finding is consistent with the results of another recent meta-analysis (44). Moreover, our results suggested a similar safety profile between percutaneous RFA and MWA since the number of severe complications appeared to be low with both techniques.
The results regarding OS may be considered the most interesting since the analysis detected a significantly better 1year OS in the MWA group. Nonetheless, this outcome was not confirmed in the 3 years analysis. However, we suggest that only three RCTs were considered for the 1-year OS and for the 3-year OS analyses, and only two out of the three were included in both, due to lack of data. We chose to include only RCTs in our study to get a more homogeneous sample, to prevent the risk of selection and operative bias and to eliminate possible outcome modifiers (e.g. different kind of 
treatments for local recurrence). Also, for the same purpose, we decided to consider only early stage HCCs (BCLC 0-A) to avoid that more severe liver function impairment could influence patient outcomes in terms of survival, treatmentrelated complications and chance to receive further treatments. In recent years, three other systematic reviews and metaanalyses have published regarding the same comparison (18, $19,44)$. In all the aforementioned studies, a small number of RCTs was included; conversely, several observational case control or cohort studies were selected in the analyses. Facciorusso et al. (19) reported no significant differences between RFA and MWA in terms of CA, OS and major complications rate. However, this study considered a very heterogeneous population including also Child-Pugh $\mathrm{C}$ patients and stage higher than BCLC 0-A. Regarding LR rate, conversely, the authors found that MWA was significantly superior to RFA when considering only patients with high tumor burden. In the meta-analysis by Tan et al. (44), similar results were reported, with a significantly lower local recurrence rate only for patients treated with laparoscopic MWA compared to laparoscopic RFA. Even more recently, Glassberg (18) suggested a statistically lower LR for MWA versus RFA, especially among patients with larger nodules $(\geq 2.5 \mathrm{~cm})$ and when higher frequencies were used. Nevertheless, in the study by Glassberg not only HCCs, but also metastases from many different primary tumors were included. Furthermore, 4 of the 28 included studies compared RFA and MWA associated with another local treatment, TACE. As previously stated, in our meta-analyses we provided a homogeneous sample, also due to the randomized selection that can provide more precise results for the specific setting. However, several limitations of this meta-analysis should be noted. First, just a small number of studies was analyzed, in a period ranging from 2002 to 2020, thus involving a big technology gap among percutaneous MWA techniques, notably improved in the last decade. Furthermore, CT scan at 1 month after the ablative technique was performed in only four out of five RCTs and no subgroup analyses were conducted for larger nodules. Finally, OS was evaluated only in 3 out of the 5 selected studies, due to missing data.

\section{Conclusion}

Our results indicate a similar efficacy and safety between RFA and MWA for early HCC treatment. Although current meta-analysis suggests slight advantages using MWA over RFA in OS terms, further evidences and high-quality RCTs are needed in order to further validate these results.

\section{Conflicts of Interest}

The Authors have stated that they have no conflicts of interest in relation to this study.

\section{Authors' Contributions}

ADR, AR: Concept, design, statistical analysis and final review; CB: concept, design and final review; ST, AP, GF, VM, NT, EM, CF: data collection and final review; CS, GB: final review and approval.

\section{References}

1 Forner A, Reig M and Bruix J: Hepatocellular carcinoma. Lancet 391(10127): 1301-1304, 2018. PMID: 29307467. DOI: 10.1016/S0140-6736(18)30010-2

2 Tang A, Hallouch O, Chernyak V, Kamaya A and Sirlin CB: Epidemiology of hepatocellular carcinoma: target population for surveillance and diagnosis. Abdom Radiol (NY) 43(1): 13-25, 2018. PMID: 28647765. DOI: 10.1007/s00261-017-1209-1

3 Park JW, Chen M, Colombo M, Roberts LR, Schwartz M, Chen P-J, Kudo M, Johnson P, Wagner S, Orsini LS and Sherman M: Global patterns of hepatocellular carcinoma management from diagnosis to death: the bridge study. Liver Int 35(9): 2155-2166, 2015. PMID: 25752327. DOI: $10.1111 /$ liv. 12818

4 Pang TC and Lam VW: Surgical management of hepatocellular carcinoma. World J Hepatol 7: 245-252, 2015. PMID: 25729479. DOI: $10.4254 /$ wjh.v7.i2.245

5 Personeni N and Rimassa L: Hepatocellular carcinoma: A global disease in need of individualized treatment strategies. J Oncol Pract 13(6): 368-369, 2017. PMID: 28605613. DOI: 10.1200/JOP.2017.024604

6 De Lorenzo S, Tovoli F, Barbera MA, Garuti F, Palloni A, Frega G, Garajova I, Rizzo A, Trevisani F and Brandi G: Metronomic capecitabine $v s$. best supportive care in Child-Pugh B hepatocellular carcinoma: a proof of concept. Sci Rep $8(1)$ : 9997, 2018. PMID: 29968763. DOI: 10.1038/s41598-01828337-6

7 Ricci AD, Rizzo A, Novelli M, Tavolari S, Palloni A, Tober N, Abbati F, Mollica V, DE Lorenzo S, Turchetti D, DI Marco M and Brandi G: Specific toxicity of maintenance olaparib versus placebo in advanced malignancies: a systematic review and meta-analysis. Anticancer Res 40(2): 597-608, 2020. PMID: 32014900. DOI: 10.21873/anticanres.13989

8 Bruix J, Reig $M$ and Sherman M: Evidence-based diagnosis, staging, and treatment of patients with hepatocellular carcinoma. Gastroenterology 150(4): 835-853, 2016. PMID: 26795574. DOI: $10.1053 /$ j.gastro.2015.12.041

9 Adhoute X, Penaranda G, Raoul JL, Le Treut P, Bollon E, Hardwigsen J, Castellani $\mathrm{P}$, Perrier $\mathrm{H}$ and Bourlière M: Usefulness of staging systems and prognostic scores for hepatocellular carcinoma treatments. World J Hepatol 8(17): 703-715, 2016. PMID: 27330679. DOI: 10.4254/wjh.v8.i17.703

10 Cucchetti A, Mazzaferro V, Pinna AD, Sposito C, Golfieri R, Serra C, Spreafico C, Piscaglia F, Cappelli A, Bongini M, Cucchi $\mathrm{M}$ and Cescon M: Average treatment effect of hepatic resection versus locoregional therapies for hepatocellular carcinoma. Br J Surg 104(12): 1704-1712, 2017. PMID: 28745399. DOI: $10.1002 /$ bjs.10613

11 Couri T and Pillai A: Goals and targets for personalized therapy for HCC. Hepatol Int 13(2): 125-137, 2019. PMID: 30600478. DOI: $10.1007 / \mathrm{s} 12072-018-9919-1$

12 Brandi G, Rizzo A, Dall'Olio FG, Felicani C, Ercolani G, Cescon M, Frega G, Tavolari S, Palloni A, De Lorenzo S, Abbati 
F, Mollica V, Ricci AD and Serra C: Percutaneous radiofrequency ablation in intrahepatic cholangiocarcinoma: a retrospective, single-center experience. Inter J Hyperthermia 37(1): 479-485, 2020. PMID: 32396398. DOI: 10.1080/ 02656736.2020 .1763484

13 Germani G, Pleguezuelo M, Gurusamy K, Meyer T, Isgrò G and Burroughs AK: Clinical outcomes of radiofrequency ablation, percutaneous alcohol and acetic acid injection for hepatocelullar carcinoma: a meta-analysis. J Hepatol 52: 380-388, 2010. PMID: 20149473. DOI: 10.1016/j.jhep.2009.12.004

14 Tiong L and Maddern GJ: Systematic review and meta-analysis of survival and disease recurrence after radiofrequency ablation for hepatocellular carcinoma. Br J Surg 98: 1210-1224, 2011. PMID: 21766289. DOI: 10.1002/bjs.7669

15 Dendy MS, Ludwig JM, Stein SM and Kim HS: Locoregional therapy, immunotherapy and the combination in hepatocellular carcinoma: Future directions. Liver Cancer 8(5): 326-340, 2019. PMID: 31768343. DOI: 10.1159/ 000494843

16 Inchingolo R, Posa A, Mariappan M and Spiliopoulos S: Locoregional treatments for hepatocellular carcinoma: Current evidence and future directions. World J Gastroenterol 25(32): 4614-4628, 2019. PMID: 31528090. DOI: 10.3748/ wjg.v25.i32.4614

17 Serra C, Cucchetti A, Felicani C, Mosconi C, De Cinque A, Golfieri R, Andreone P, Ercolani G, Maroni L, Ravaioli M, D'Errico A, Pinna AD and Cescon M: Assessment of radiofrequency ablation efficacy for hepatocellular carcinoma by histology and pretransplant radiology. Liver Transpl 25(1): 8897, 2019. PMID: 3041550. DOI: 10.1002/lt.25381

18 Glassberg MB, Ghosh S, Clymer JW, Wright GJW, Ferko N and Amaral JF: Microwave ablation compared with hepatic resection for the treatment of hepatocellular carcinoma and liver metastases: a systematic review and meta-analysis. World J Surg Oncol 17(1): 98, 2019. PMID: 31182102. DOI: 10.1186/s12957019-1632-6

19 Facciorusso A, Di Maso M and Muscatiello N: Microwave ablation versus radiofrequency ablation for the treatment of hepatocellular carcinoma: A systematic review and metaanalysis. Int J Hyperthermia 32(3): 339-344, 2016. PMID: 26794414. DOI: 10.3109/02656736.2015.1127434

20 Vietti Violi N, Duran R, Guiu B, Cercueil JP, Aube C, Digklia A, Pache I, Deltenre P, Knebel JF and Denys A: Efficacy of microwave ablation versus radiofrequency ablation for the treatment of hepatocellular carcinoma in patients with chronic liver disease: a randomised controlled phase 2 trial. Lancet Gastroenterol Hepatol 3: 317-325, 2018. PMID: 29503247. DOI: 10.1016/S468-1253(18)30029-3

21 Shibata T, Iimuro Y, Yamamoto Y, Maetani Y, Ametani F, Itoh K and Konishi J: Small hepatocellular carcinoma: comparison of radio-frequency ablation and percutaneous microwave coagulation therapy. Radiology 223: 331-337, 2002. PMID: 11997534. DOI: $10.1148 /$ radiol.2232010775

22 Yu J, Yu XL, Han ZY, Cheng ZG, Liu FY, Zhai HY, Mu MJ, Liu YM and Liang P: Percutaneous cooled-probe microwave versus radiofrequency ablation in early-stage hepatocellular carcinoma: a phase III randomised controlled trial. Gut 66(6): 1172-1173, 2017. PMID: 27884919. DOI: 10.1136/gutjnl-2016-312629

23 Kamal A, Elmoety AAA, Rostom YAM, Shater MS and Lashen SA: Percutaneous radiofrequency versus microwave ablation for management of hepatocellular carcinoma: a randomized controlled trial. J Gastrointest Oncol 10: 562-571, 2019. PMID: 31183208. DOI: $10.21037 /$ jgo.2019.01.34

24 Abdelaziz A, Elbaz T, Shousha HI, Mahmoud S, Ibrahim M, Abdelmaksoud A and Nabeel M: Efficacy and survival analysis of percutaneous radiofrequency versus microwave ablation for hepatocellular carcinoma: an Egyptian multidisciplinary clinic experience. Surg Endosc 28(12): 3429-3434, 2014. PMID: 24935203. DOI: $10.1007 / \mathrm{s} 00464-014-3617-4$

25 Moher D, Liberati A, Tetzlaff J, Altman DG and PRISMA Group: Preferred reporting items for systematic reviews and meta-analyses: the PRISMA statement. Int J Surg 8(5): 336-341, 2010. PMID: 20171303. DOI: 10.1016/j.ijsu.2010.02.007

26 Higgins J and Green S: Cochrane Handbook for Systematic Reviews of Interventions Version 5.1.0. Cochrane Collab, 2011.

27 Clavien PA, Barkun J, de Oliveira ML, Vauthey JN, Dindo D, Schulick RD, de Santibanes E, Pekolj J, Slanjamenac K, Bassi $\mathrm{C}$ and Graf R: The Clavien-Dindo classification of surgical complications: five-year experience. Ann Surg 250: 187-196, 2009. PMID: 19638912. DOI: 10.1097/SLA.0b013e318b13ca2

28 Di Vece F, Tombesi P, Ermili F, Maraldi C and Sartori S: Coagulation areas produced by cool-tip radiofrequency ablation and microwave ablation using a device to decrease back-heating effects: a prospective pilot study. Cardiovasc Intervent Radiol 37(3): 723-729, 2014. PMID: 24196263. DOI: 10.1007/s00270013-0733-9

29 Tian W: A randomised comparative trial on liver tumors treated with ultrasound-guided percutaneous radiofrequency versus microwave ablation. Chin J Hepatobiliary Surg 20: 119-122, 2014.

30 Sheta E, El-Kalla F, El-Gharib M, Kobtan A, Elhendawy M, Abd-Elsalam S, Mansour L and Amer I: Comparison of singlesession transarterial chemoembolization combined with microwave ablation or radiofrequency ablation in the treatment of hepatocellular carcinoma: a randomized-controlled study. Eur J Gastroenterol Hepatol 28: 1198-1203, 2016. PMID: 27362551. DOI: 10.1097/MEG.0000000000000688

31 Inchingolo R, Posa A, Mariappan M and Spiliopoulos S: Locoregional treatments for hepatocellular carcinoma: Current evidence and future directions. World J Gastroenterol 25(32): 4614-4628, 2019. PMID: 31528090. DOI: $10.3748 / \mathrm{wjg}$. v25.i32.4614

32 Rizzo A, Frega G, Ricci AD, Palloni A, Abbati F, DE Lorenzo S, Deserti M, Tavolari S and Brandi G: Anti-EGFR monoclonal antibodies in advanced biliary tract cancer: a systematic review and meta-analysis. In Vivo 34(2): 479-488, 2020. PMID: 32111744. DOI: 10.21873/invivo.11798

33 Lee DH and Lee JM: Recent advances in the image-guided tumor ablation of liver malignancies: Radiofrequency ablation with multiple electrodes, real-time multimodality fusion imaging, and new energy sources. Korean J Radiol 19: 545-559, 2018. PMID: 29962861. DOI: 10.3348/kjr.2018.19.4.545

34 Hinshaw JL, Lubner MG, Ziemlewicz TJ, Lee FT and Brace CL: Percutaneous tumor ablation tools: microwave, radiofrequency, or cryoablation-what should you use and why? Radiographics 34 : 1344-1362, 2014. PMID: 25208284. DOI: 10.1148/rg.345140054

35 European Association for the Study of the Liver: EASL Clinical Practice Guidelines: Management of hepatocellular carcinoma. J Hepatol 69: 182-236, 2018. PMID: 29628281. DOI: 10.1016/ j.jhep.2018.03.019 
36 Kim YS, Lim HK, Rhim $\mathrm{H}$ and Lee MW: Ablation of hepatocellular carcinoma. Best Pract Res Clin Gastroenterol 28: 897-908, 2014. PMID: 25260316. DOI: 10.1016/j.bpg. 2014.08.011

37 Crocetti L, Bargellini I and Cioni R: Loco-regional treatment of HCC: Current status. Clin Radiol 72: 626-635, 2017. PMID: 28258743. DOI: $10.1016 /$ j.crad.2017.01.013

38 Dou JP, Liang P and Yu J: Microwave ablation for liver tumors. Abdom Radiol 41: 650-658, 2016. PMID: 26880177. DOI: 10.1007/s00261-016-0662-6

39 Ding J, Jing X, Liu J, Wang Y, Wang F, Wang Y and Du Z: Complications of thermal ablation of hepatic tumours: comparison of radiofrequency and microwave ablative techniques. Clin Radiol 68: 608-615, 2013. PMID: 23399463. DOI: $10.1016 /$ j.crad.2012.12.008

40 Lahat E, Eshkenazy R, Zendel A, Zakai BB, Maor M, Dreznik $\mathrm{Y}$ and Ariche A: Complications after percutaneous ablation of liver tumors: a systematic review. Hepatobiliary Surg Nutr 3: 317-323, 2014. PMID: 25392844. DOI: $10.3978 /$ j.issn.23043881.2014.09.07

41 Luo W, Zhang Y, He G, Yu M, Zheng M, Liu L and Zhou X: Effects of radiofrequency ablation versus other ablating techniques on hepatocellular carcinomas: a systematic review and meta-analysis. World J Surg Oncol 15: 126, 2017. PMID: 28693505. DOI: $10.1186 / \mathrm{s} 12957-017-1196-2$
42 Chinnaratha MA, Chuang MY, Fraser RJ, Woodman RJ and Wigg AJ: Percutaneous thermal ablation for primary hepatocellular carcinoma: A systematic review and metaanalysis. J Gastroenterol Hepatol 31: 294-301, 2016. PMID: 26114968. DOI: $10.1111 /$ jgh.13028

43 Pompili M, Saviano A, de Matthaeis N, Cucchetti A, Ardito F, Federico B, Brunello F, Pinna AD, Giorgio A, Giulini SM, De Sio I, Torzilli G, Fornari F, Capussotti L, Guglielmi A, Piscaglia F, Aldrighetti L, Caturelli E, Calise F, Nuzzo G, Rapaccini GL and Giuliante F: Long-term effectiveness of resection and radiofrequency ablation for single hepatocellular carcinoma $\leq 3$ $\mathrm{cm}$. Results of a multicenter Italian survey. J Hepatol 59: 89-97, 2013. PMID: 23523578. DOI: 10.1016/j.jhep.2013.03.009

44 Tan W, Deng Q, Lin S, Wang Y and Xu G: Comparison of microwave ablation and radiofrequency ablation for hepatocellular carcinoma: a systematic review and metaanalysis. Int J Hyperthermia 36(1): 264-272, 2019. PMID: 30676100. DOI: 10.1080/02656736.2018.1562571

Received June 24, 2020

Revised July 14, 2020

Accepted July 15, 2020 